\title{
Captopril-enhanced renal scintigraphy in the diagnosis of pediatric hypertension
}

\author{
György Sandor Reusz • Eva Kis • Orsolya Cseprekál • \\ Attila Jozsef Szabó • Eva Kis
}

Received: 21 August 2009 /Accepted: 21 August 2009/Published online: 20 October 2009

(C) IPNA 2009

\begin{abstract}
Hypertension in childhood is no longer a rare condition mainly secondary to renal, or renovascular diseases, as a growing proportion of children are obese and hypertensive, with the phenotype of metabolic syndrome. Thus, we need to reconsider our practice in the examination of the hypertensive child and redefine the place of non-invasive methods for screening of renovascular hypertension, and specifically, to evaluate the value of captopril-enhanced renal scintigraphy at the two ends of the palette: the obese child with hypertension and the severely hypertensive prepubertal child. Renal artery stenosis in children is mainly due to fibromuscular dysplasia and stenoses associated with syndromes involving single or multiple smaller branch vessels. This explains the low specificity and sensitivity of the color-Doppler ultrasound method and captopril renal scintigraphy. Even the more sophisticated computed tomography (CT) and magnetic resonance imaging (MRI) angiographic techniques are, at present, not sensitive enough to exclude stenoses of the small branches definitely. Thus, children in whom there is a strong suggestion of renovascular hypertension should undergo angiography with a view to endovascular treatment, as non-invasive imaging has no significant benefit and might lead to a delay in treatment. In the cases when the probability of renovascular disease is moderate a basic
\end{abstract}

\footnotetext{
G. S. Reusz $(\bowtie) \cdot$ E. Kis · O. Cseprekál · A. J. Szabó Pediatric Nephrology, First Department of Pediatrics, Semmelweis University,

Bókay János u. 53-54,

Budapest 1083, Hungary

e-mail: reusz@gyer1.sote.hu

E. Kis

Pediatric Radiology, First Department of Pediatrics, Semmelweis University,

Budapest, Hungary
}

assessment of renal function and structure is sufficient. In the neonate, catheter-associated thromboembolic disease is among the most common causes hypertension. It should be controlled medically until the patient is old enough to undergo angiography and angioplasty successfully. Thus, in this age group, there is a place for functional imaging with renal sonography and angiotensin-converting enzyme inhibitor (ACEI) renography to detect hemodynamically significant renovascular disease, with the limitations mentioned above. However, the rapid technical evolution of non-invasive methods requires periodic re-consideration of the actual standpoints.

Keywords Vascular · Hypertension · Captopril . Scintigraphy $\cdot$ Angiography

\section{Introduction}

Not much more than one decade ago the diagnostic workup of pediatric hypertension seemed to be a solid field with rapidly evolving non-invasive diagnostic procedures that promised to eliminate the need for the more invasive classical diagnostic tests [1]. The emergence of the new epidemic of pediatric hypertension from obesity becoming the third most common chronic disease in the industrialized world, the monochromic picture has been somewhat blurred [2]. The prevalence of childhood obesity has more than tripled over the past 30 years, and it now approaches or exceeds $20 \%$ in some pediatric age groups $[1,3,4]$. Obese children are more likely to have elevated systolic or diastolic blood pressure (BP) than non-obese children, and body mass index (BMI) is a significant predictor of elevated BP. Thus, the old premise, that pediatric hypertension is a rare disease and mainly secondary to renal, 
renovascular or vascular diseases, has to be refined. A growing proportion of children are simply overweight and definitely have the phenotype of obesity with numerous sequelae and co-morbidities such as impaired glucose tolerance, dyslipidemia, elevated BP, hepatic disease, orthopedic problems, and psychosocial disorders. That is why the examination of the hypertensive child needs particular considerations and new skills from the side of pediatric nephrologists - the ones historically caring for hypertensive children.

One of the questions is how extensive the examination of the hypertensive child should be, and, in this context, whether the available non-invasive methods [various ultrasound, nuclear medicine, computed tomography (CT) and magnetic resonance imaging (MRI) techniques] for screening renovascular hypertension are sensitive and specific enough to confirm or to rule out the involvement of the renal vessels. Specifically, is there still a place for captopril-enhanced renal scintigraphy among these methods at and between the two ends of the palette: the obese child with hypertension, with high probability of 'essential' hypertension, and the severely hypertensive, lean, prepubertal child with the classical diagnosis of renal hypertension?

\section{Captopril-enhanced renal scintigraphy}

The method described by Gates [5,6] is based on the principle that reduced renal perfusion pressure due to renal artery stenosis results in an angiotensin 2-mediated efferent arteriolar vasoconstriction. The subsequent rise of the transglomerular pressure gradient allows the kidney to maintain glomerular filtration rate (GFR) even when perfusion pressure to the glomerulus is reduced. Angiotensin-converting enzyme (ACE) inhibition interrupts the renin-angiotensin system and reduces that compensatory constriction of the postglomerular arteriole. The ensuing dilatation lowers the glomerular transcapillary forces, leading to a decrease in GFR. ACE inhibitors also inhibit kininase 2, which inactivates bradykinin. That potent vasodilator accumulates following ACE inhibition and provides a second mechanism for the development of an abnormal renogram curve.

The decrease on the individual kidney's glomerular filtration rate induced by ACE inhibition can be assessed by radionuclide imaging with the use of a purely glomerular agent, such as technetium-99m diethylene triamine penta-acetic acid (DTPA) or by tubular agents, such as technetium-99m mercapto-acetyl triglycine (MAG3) or technetium-99m dimercapto-succinic acid (DMSA). The decrease in GFR is manifested as a change in absolute or relative renal uptake of DTPA when compared to that of the baseline study. With tubular tracers, renovascular hypertension is usually best detected by parenchymal retention following ACE inhibition. Parenchymal retention is also secondary to the decreased flow in the renal tubules and delayed washout of the radionuclide from the tubules and tubular lumen [7-9]. In view of the high incidence of intrarenal disease in children (see below), whole-kidney cortical time-activity curves may not reveal any abnormality. It has been suggested that time-activity and regional cortical time-activity curves be used, and that the images be evaluated visually, to improve eventually the sensitivity of the method [10].

Numerous studies have been undertaken, mainly in adults, that show relatively high sensitivities and specificities (68-94\% and 70-98\%, respectively) for the detection of renovascular disease $[7-9,11]$. It has been considered as a promising, simple, non-invasive method in pediatrics [1]. However, although the idea is very elegant, in practice the results have been inconsistent [12]. Published experience in children is scarce, not the least because it is difficult for good quality research to be performed in a field where there are few patients and imaging technology is rapidly evolving. Studies both supporting [13-15] and questioning its value in the diagnostics of pediatric renovascular disease have been published $[12,16]$. In addition, negative results are less likely to be published; thus, a publication bias can not be ruled out.

According to the data of Abdulsamea, published in this issue of Pediatric Nephrology [17], the ability of pre- and post-captopril renal scintigraphy to predict renovascular disease (RVD) in children has sensitivity and specificity values and positive and negative predictive values of $48 \%$, $73 \%, 76 \%$, and $51 \%$, respectively. The authors conclude that pre- and post-captopril renal scintigraphy is unable to predict RVD accurately in children.

\section{Etiology of renal artery stenosis in children, and its implications}

The apparent discrepancy in the utility of captopril renal scans for children and adults comes, in great part, from the etiology and anatomical distribution of renal artery stenosis in children. The most common condition causing renovascular disease in childhood is fibromuscular dysplasia, which is reported in approximately $70 \%$ of patients with renovascular hypertension [12, 14, 18, 19]. This is in contrast to the situation in adults, where $60 \%$ of cases of renovascular disease are due to atherosclerosis at the ostium or on the main branch of the renal artery $[20,21]$. Other cases of pediatric renal artery stenosis (RAS) are associated with established disorders, including vasculitides (Takayasu disease, Moya-Moya), syndromes (Turner, Marfan, Williams, 
Klippel-Trenaunay-Weber, mid-aortic), neurofibromatosis and previous renal artery surgery. It is to be noted that the etiology presents striking geographical differences, with Takayasu arteritis being the predominant cause in India and South Africa [22, 23], possibly due to the high incidence of tuberculosis in those regions.

Children with co-morbid conditions often have complex lesions that can be multiple and/or include long-segment stenoses $[24,25]$ while those without co-morbid diseases have single and focal lesions that involve smaller branch vessels. Thus, the extremely appealing method of captoprilenhanced renal scintigraphy is, in practice, not sufficient enough to exclude treatable renovascular disease in children [12] even if the ones who, on the basis of a thorough clinical examination, are more likely to harbor a renal artery stenosis, are pre-selected, as suggested by Lagomarsino et al. [13]. This technique is particularly unhelpful if there is aortic or bilateral renal artery stenosis or the involvement of secondary branches of the renal artery, which is quite common in children with hypertension [26].

\section{Doppler ultrasound imaging, CT and MRI}

Although not fully within the scope of this commentary, the role of the new ultrasound, CT and MRI techniques as potential screening methods should also be discussed briefly.

The abdominal aorta can been seen and measured by ultrasound (US). However, the renal arteries are not always reliably visualized in children. For this reason, various Doppler parameters have been used as indirect indicators of renal artery stenosis, including peak systolic velocity (PSV), acceleration time and resistive index [27-32]. Even with the use of these indicators, false-positive and falsenegative results are not rare, and the method remains insensitive for the detection of the stenoses of accessory renal arteries. Thus, there are major limitations to ultrasound imaging for the diagnosis of RAS in children, including dependency on operator expertise [26] and poor detection of stenoses of small branches or accessory or multiple renal arteries, which are quite common in children with renovascular disease.

Clearly, CT angiography is adequate for diagnostic evaluation of most aortic pathology. Its role in the main renal arteries and their branches is currently unproven in children. Recent technical developments using multiple (eight, 16, 64) detectors may make it a more useful technique. However, the high radiation dose and the use of iodine-containing contrast material will still be of concern in pediatrics [33].

Magnetic resonance angiography (MRA) is currently capable of accurate depiction of the aorta in children [34], but, even in the main renal arteries, image quality is not always adequate. This may change as spatial and temporal resolution improves. It is possible that perfusion techniques will permit the indirect detection of abnormalities of segmental renal arteries, though recent technology still requires the cooperation of the child (breath holding) or necessitates the use of general anesthesia [33].

\section{The specific case of renovascular hypertension of infants}

The specificity of infantile hypertension resides in the unique etiology, the delicate vasculature and the difficulty of blood pressure measurement. The topic has been extensively reviewed [15]. The aspects concerning etiology and imaging will be considered here.

Hypertension often occurs in the neonatal intensive care unit as a result of invasive manipulation of the umbilical arteries or veins. Most cases of hypertension in infants are caused by renovascular, renal parenchymal, or cystic disease [35]. Renovascular disorders may account for approximately one-half of the cases of neonatal hypertension [36]. Catheter-associated thromboembolic disease is the most common cause in this category. This may propagate directly or embolize to the renal artery, causing regions of ischemia or infarction and increased renin release. Other renovascular etiologies include mid-aortic coarctation, congenital renal artery stenosis, fibromuscular dysplasia and renal vein thrombosis.

Table 1 Factors indicating a strong suggestion of renovascular hypertension

Indication

- Severe hypertension ( $>99$ percentile $+5 \mathrm{mmHg}$ compared with ageand height-matched controls)

- Poorly controlled hypertension (need of two or more antihypertensive drugs)

- Secondary symptoms of high blood pressure

Cerebral symptoms (headache, facial palsy, seizures, encephalopathy) Cardiac failure

- Known or suspected previous vascular insult

- Diagnosis of a syndrome with a high risk of vascular disease

Neurofibromatosis, tuberous sclerosis, Williams' syndrome

- Signs of vasculitis

Takayasu's disease

- Previous trauma or radiation

- Transplanted kidneys

- Bruit heard over renal artery or arteries

- Neonatal: renal artery thrombosis or umbilical artery catheterization

- Laboratory: raised concentration of peripheral plasma renin, moderate hypokalemia, and metabolic alkalosis 
Finally, extrinsic compression of the renal artery can result from hydronephrosis, tumor, or hematoma (e.g. from adrenal hemorrhage) [37].

As the critically ill neonate is often ventilated and it is difficult for the patient to be moved to the radiology unit, initial screening is usually performed at the bedside, with gray-scale sonography used to identify renal parenchymal or collecting system abnormalities, including mass lesions and congenital anomalies. Imaging with color and duplex Doppler sonography detects renal arterial or aortic thrombosis and alterations in the arterial waveform caused by intrinsic or extrinsic renal artery narrowing, but the more subtle changes in the renal vasculature (disease in accessory renal arteries or in small segmental intrarenal arteries) often go undetected.

Angiography should be reserved for older children for whom interventional percutaneous angioplasty may be feasible. The condition of the young infant with hypertension caused by renal artery stenosis should be controlled medically until the patient is old enough to undergo angiography and angioplasty successfully.

Thus, there is a place for further non-invasive 'screening' in this age group, with the limitations mentioned above. Functional imaging with angiotensin-converting enzyme inhibitor (ACEI) renography should follow renal sonography to detect hemodynamically significant renovascular disease; intravenous administration of enalaprilat is the preferred form of ACE inhibition. CT angiography and MR angiography may not adequately resolve the small intrarenal vessels, which are frequently the culprits in renovascular hypertension of infancy [15].

\section{Practical considerations}

For the time being, a reasonable compromise is to try to identify groups of patients who have a high probability of renovascular disease [33] (Table 1). Children in whom there is a strong suggestion of renovascular disease should undergo angiography (and renal vein renin sampling if appropriate) with a view to endovascular treatment. Noninvasive imaging in the above-mentioned patients has no significant benefit and might lead to a delay in treatment $[19,33]$.

The clinical algorithm developed by Tullus et al. is seemingly more permissive with regard to non-invasive techniques. However, in their algorithm, the eventual negative results of captopril-enhanced renal scintigraphy and/or CT angiography and/or MR angiography are overwritten, and angiography is proposed when there is a strong clinical suggestion of renovascular involvement or poorly controllable hypertension; thus, the final result does not differ from that of the procedure proposed above [19].
The question remains of the role of non-invasive imaging when the probability of renovascular disease is only moderate. The possibility that obese pubertal/postpubertal children with borderline or moderate hypertension harbor renovascular disease with the need for angiologic intervention is small. There is definitely no need for pseudo-investigations aimed exclusively at documenting that "renovascular disease has been excluded". Their workup should include a basic assessment of renal function and structure, with more complex imaging being undertaken only where there is the suggestion of renovascular disease, as presented in Table 1 .

In conclusion, medicine is still as much art as science. Finding the balance between the feasible and the reasonable is not always easy or simple. The rapid technical evolution of non-invasive methods requires periodic re-consideration of the actual standpoints. Studies are the bases of recommendations and guidelines; pediatric hypertension is the field where studies and guidelines should improve outcomes and avoid unnecessary investigation.

Acknowledgement This study was supported by the Hungarian National Research grants OTKA-071730, NNF 78846 and TAMOP4.2.2-08/1/-KMR-2008-0004.

\section{References}

1. Dillon MJ (1997) The diagnosis of renovascular disease. Pediatr Nephrol 11:366-372

2. Flynn JT (2008) Pediatric hypertension: recent trends and accomplishments, future challenges. Am J Hypertens 21:605-612

3. Chrzanowska M, Koziel S, Ulijaszek SJ (2007) Changes in BMI and the prevalence of overweight and obesity in children and adolescents in Cracow, Poland, 1971-2000. Econ Hum Biol $5: 370-378$

4. Sorof JM, Lai D, Turner J, Poffenbarger T, Portman RJ (2004) Overweight, ethnicity, and the prevalence of hypertension in school-aged children. Pediatrics 113:475-482

5. Gates GF (1982) Glomerular filtration rate: estimation from fractional renal accumulation of $99 \mathrm{mTc}-\mathrm{DTPA}$ (stannous). AJR Am J Roentgenol 138:565-570

6. Gates GF (1983) Split renal function testing using Tc-99m DTPA. A rapid technique for determining differential glomerular filtration. Clin Nucl Med 8:400-407

7. Dondi M (1991) Captopril renal scintigraphy with $99 \mathrm{mTc}-$ mercaptoacetyltriglycine (99mTc-MAG3) for detecting renal artery stenosis. Am J Hypertens 4:737S-740S

8. Johansson M, Jensen G, Aurell M, Friberg P, Herlitz H, Klingenstierna H, Volkmann R (2000) Evaluation of duplex ultrasound and captopril renography for detection of renovascular hypertension. Kidney Int 58:774-782

9. McLean AG, Hilson AJ, Scoble JE, Maher ER, Thakrar DS, Moorhead JF, Sweny P (1992) Screening for renovascular disease with captopril-enhanced renography. Nephrol Dial Transplant 7:211-215

10. Cheung WSK, Wong KN, Wong YC, Ma KM (2004) Segmental renal artery stenosis diagnosed with captopril renography in a child. Pediatr Radiol 34:636-639 
11. Thorsson O, Bjuväng A, Granerus G (2009) Advantages of standardized criteria for the interpretation of angiotensin-converting enzyme inhibition renography. Nucl Med Commun 30:449-454

12. Ng CS, de Bruyn R, Gordon I (1997) The investigation of renovascular hypertension in children: the accuracy of radioisotopes in detecting renovascular disease. Nucl Med Commun 18:1017-1028

13. Lagomarsino E, Orellana $P$, Muñoz J, Velásquez C, Cavagnaro F, Valdés F (2004) Captopril scintigraphy in the study of arterial hypertension in pediatrics. Pediatr Nephrol 19:66-70

14. Broekhuizen-de Gast HS, Tiel-van Buul MM, Van Beek EJ (2001) Severe hypertension in children with renovascular disease. Clin Nucl Med 26:606-609

15. Roth CG, Spottswood SE, Chan JC, Roth KS (2003) Evaluation of the hypertensive infant: a rational approach to diagnosis. Radiol Clin North Am 41:931-944

16. Minty I, Lythgoe MF, Gordon I (1993) Hypertension in paediatrics: can pre- and post-captopril technetium-99m dimercaptosuccinic acid renal scans exclude renovascular disease? Eur J Nucl Med 20:699-702

17. Abdulsamea S, Anderson P, Biassoni L, Brennan E, McLaren CA, Marks SD, Roebuck DJ, Selim S, Tullus K (2009) Pre- and postcaptopril renal scintigraphy as a screening test for renovascular hypertension in children. Pediatr Nephrol. doi:10.1007/s00467009-1304-9

18. Makker SP, Moorthy B (1979) Fibromuscular dysplasia of renal arteries. An important cause of renovascular hypertension in children. J Pediatr 95:940-945

19. Tullus K, Brennan E, Hamilton G, Lord R, McLaren CA, Marks SD, Roebuck DJ (2008) Renovascular hypertension in children. Lancet 371:1453-1463

20. Wise KL, McCann RL, Dunnick NR, Paulson DF (1988) Renovascular hypertension. J Urol 140:911-924

21. de Mast Q, Beutler JJ (2009) The prevalence of atherosclerotic renal artery stenosis in risk groups: a systematic literature review. J Hypertens 27:1333-1340

22. Kumar P, Arora P, Kher V, Rai PK, Gulati S, Baijal SS, Kumar S (1996) Malignant hypertension in children in India. Nephrol Dial Transplant 11:1261-1266

23. McCulloch M, Andronikou S, Goddard E, Sinclair P, Lawrenson J, Mandelstam S, Beningfield SJ, Millar AJ (2003) Angiographic features of 26 children with Takayasu's arteritis. Pediatr Radiol 33:230-235

24. Courtel JV, Soto B, Niaudet P, Gagnadoux MF, Carteret M, Quignodon JF, Brunelle F (1998) Percutaneous transluminal angioplasty of renal artery stenosis in children. Pediatr Radiol 28:59-63
25. McTaggart SJ, Gulati S, Walker RG, Powell HR, Jones CL (2000) Evaluation and long-term outcome of pediatric renovascular hypertension. Pediatr Nephrol 14:1022-1029

26. Vo NJ, Hammelman BD, Racadio JM, Strife CF, Johnson ND, Racadio JM (2006) Anatomic distribution of renal artery stenosis in children: implications for imaging. Pediatr Radiol 36:10321036

27. Working Group on Renovascular Hypertension (1987) Detection, evaluation, and treatment of renovascular hypertension. Final report. Working Group on Renovascular Hypertension. Arch Intern Med 147:820-829

28. Brun P, Kchouk H, Mouchet B, Baudouin V, Raynaud A, Loirat C, Azancot-Benisty A (1997) Value of Doppler ultrasound for the diagnosis of renal artery stenosis in children. Pediatr Nephrol 11:27-30

29. Li JC, Wang L, Jiang YX, Dai Q, Cai S, Lv K, Qi ZH (2006) Evaluation of renal artery stenosis with velocity parameters of Doppler sonography. J Ultrasound Med 25:735-742

30. Eklöf H, Ahlström H, Magnusson A, Andersson LG, Andrén B, Hägg A, Bergqvist D, Nyman R (2006) A prospective comparison of duplex ultrasonography, captopril renography, MRA, and CTA in assessing renal artery stenosis. Acta Radiol 47:764-774

31. Zeller T, Bonvini RF, Sixt S (2008) Color-coded duplex ultrasound for diagnosis of renal artery stenosis and as followup examination after revascularization. Catheter Cardiovasc Interv 71:995-999

32. Drieghe B, Madaric J, Sarno G, Manoharan G, Bartunek J, Heyndrickx GR, Pijls NH, De Bruyne B (2008) Assessment of renal artery stenosis: side-by-side comparison of angiography and duplex ultrasound with pressure gradient measurements. Eur Heart J 29:517-524

33. Roebuck D (2008) Childhood hypertension: what does the radiologist contribute? Pediatr Radiol 38(Suppl 3):S501-S507

34. Gandy SJ, Sudarshan TA, Sheppard DG, Allan LC, McLeay TB, Houston JG (2003) Dynamic MRI contrast enhancement of renal cortex: a functional assessment of renovascular disease in patients with renal artery stenosis. J Magn Reson Imaging 18:461-466

35. Flynn JT (2000) Neonatal hypertension: diagnosis and treatment. Pediatr Nephrol 14:332-341

36. Chandar JJ, Sfakianakis GN, Zilleruelo GE, Guerra JJ, Georgiou MF, Abitbol CL, Montane BS, Strauss J (1999) ACE inhibition scintigraphy in the management of hypertension in children. Pediatr Nephrol 13:493-500

37. Starinsky R, Manor A, Segal M (1986) Non-functioning kidney associated with neonatal adrenal hemorrhage: report of two cases. Pediatr Radiol 16:427-429 